\title{
TEORÍA DE LA EDUCACIÓN Y CIENCIAS DE LA EDUCACIÓN APLICADAS A LA CRIMINOLOGÍA: UNA PROPUESTA DE RENOVACIÓN
}

\section{EDUCATION THEORY AND EDUCATION SCIENCES APPLIED TO THE CRIMINOLOGY: A RENEWAL PROPOSE}

\author{
Wael Hikal Carreón \\ Doctorando en Filosofia con Centuación en Estudios de la Educación \\ Facultad de Filosofia y Letras \\ Universidad Autónoma de Nuevo León \\ wshe1983.2013@gmail.com \\ México, Nuevo León
}

\section{SUMARIO}

- La teoría de la educación aplicada a la criminología

- Áreas de oportunidad en la criminología educativa y criminología pedagógica

- La enseñanza universitaria de la criminología y su pertinencia social

- Conclusiones

\section{RESUMEN}

\section{RESUMEN}

En el interés de diversos autores que se muestran durante la lectura, se notará que la labor de articulación entre la teoría general de la educación y la criminología, tiene ya historia. Aquí se retoman esos trabajos para aplicarlas principalmente a las áreas de oportunidad en la criminología pedagógica y criminología educativa, resaltando procesos que pueden mejorarse para una renovación en los quéhaceres educativos, formas de impartir la enseñanza, e investigación. De inicio, se adaptan brevemente las dimensiones científicas, filosóficas y proyectivas de la educación a la criminología, esto da lugar a proseguir con el tema del mejoramiento en la criminología educativa y criminología pedagógica, contextualizando los procesos de la teoría general a estas otras. Finalmente, se destaca la importancia de la labor social de la criminología y sus profesionales, cuando se espera de estos, el proporcionar los conocimientos a los agentes del estado que están necesitados de la comprensión del problema criminal, para determinar políticas públicas.

\begin{abstract}
In the interest of various authors shown during reading, it will be noted that the work of articulation between the general theory of education and criminology, already has history. These work is resumed here to apply them mainly to areas of opportunity in pedagogical criminology and educational criminology, highlighting processes that can be improved for a renewal in educational chores, ways to teach, and research. In the beginning, the scientific, philosophical and projective dimensions of education are briefly adapted to criminology, this gives rise to continue the theme of improvement in educational criminology and pedagogical criminology, contextualizing the processes of the general theory to these others. Finally, the importance of the social work of criminology and its professionals, when expected, is highlighted, to provide knowledge to state agents who are in need of understanding the criminal problem, to determine public policy.
\end{abstract}

\section{PALABRAS CLAVE}

Criminología y ciencias de la educación; Criminología educativa; Criminología pedagógica; Enseñanza universitaria; Teoría de la educación y criminología. 


\section{KEYWORDS}

Criminology and educational sciences; Educational criminology; Pedagogical criminology; Theory of education and criminology; University teaching.

\section{LA TEORÍA DE LA EDUCACIÓN APLICADA A LA CRIMINOLOGÍA}

En el interés por especializar diversos campos de estudio con una pedagogía propia, se fue desmembrando a la pedagogía general, aportando posturas desde otras áreas del conocimiento (Colom Cañellas y Rodríguez Cruz, 1996). Tal es el caso de la criminología, que ha formado su propia, pero pobre, pedagogía criminal. Al verse los sectores públicos o privados en algunos problemas, surge la necesidad de capacitar en áreas específicas según las necesidades del grupo o del contexto (Abbot Matus, 2007).

De lo anterior, surge, según Salgado (2013) una pedagogía criminológica, que puede ser aplicada por los educadores en las aulas para enseñar los conocimientos en materia criminal desde las ópticas del derecho, psicología, antropología, trabajo social, estadística, medicina, química, entre otras del núcleo de convergencia a lo criminal (Escobar Marulanda, 2006), pero en un producto integrador enfocado como se mencionó, a lo específico criminal (Zaffaroni, 1990). Así, no fue la excepción la criminología en tomar en cuenta a las teorías de la educación como un espacio propio para el desarrollo de sus enseñanzas (Colom Cañellas y Rodríguez Cruz, 1996).

En la enseñanza de esta área, fue necesario adoptar y crear formas de didáctica, métodos, teorías, técnicas, metodologías, prácticas, entre otras áreas, que mostrarán puntos de conexión para explicar la realidad (Abbot Matus, 2007; Colom Cañellas y Rodríguez Cruz, 1996) sobre los asuntos relativos a la criminalidad y la justicia criminal (Abbot Matus, 2007). Si se parte en investigar los anales de la formación universitaria de la criminología, persiste algo pendiente, y es que no ha ocurrido del todo una sana integración de los conocimientos, por lo que los saberes se tienen parcelados y poco interactuantes (Abbot Matus, 2007; Zaffaroni, 1990).
Es necesario aplicar los contenidos fundamentales y los contenidos específicos (Colom Cañellas y Rodríguez Cruz, 1996) en la construcción de las enseñanzas de la criminología, para de la generalidad de los procesos educativos, conceptos, teorías y modelos, adaptarlos al área específica, así como el conocimiento enfocado al saber hacer, en otras palabras, una criminología educativa (Calixto Contreras, 2017) que enseñe, luego una criminología pedagógica o pedagogía criminal (Salgado, 2013). Apuntan Colom Cañellas y Rodríguez Cruz: "Hablar de las ciencias de la educación no es más que especializar, en función del objeto educativo" (pág. 53).

\section{ÁREAS DE OPORTUNIDAD EN LA CRIMINOLOGÍA EDUCATIVA Y CRIMINOLOGÍA PEDAGÓGICA}

Las formas de criminalidad van cambiando, esos actos individuales que dañan la convivencia cívica tienen volcado al mundo entero, razón tal, por la cual sea de interés a las diversas áreas del conocimiento, así como las agencias del estado, el tomar en su quéhacer, modos de colaboración, estudio, investigación, aportación, etcétera, para ayudar a detener el fenómeno (Abbot Matus, 2007). Si la criminalidad evoluciona, es innegable que las formas de estudiar desde las aulas el fenómeno criminal, también deban evolucionar (Ríos Patio, 2017).

Teniendo de referencia el cuadro Perspectiva estática o sincrónica de la endoestructura de las Ciencias de la Educación planteado por Colom Cañellas y Rodríguez Cruz (1996, pág. 48), tal modelo puede aplicarse a la enseñanza de la criminología como se explica a continuación.

Retomando a la criminología educativa (Calixto Contreras, 2017), desde la dimensión histórica, esta nos indicaría cómo se fue desarrollando la enseñanza de la criminología, antecedentes históricos; desde la dimensión científica, sus fundamentos teóricos, científicos (Colom Cañellas y Rodríguez Cruz, 1996, pág. 48). Desde la ideológica, conocer la perspectiva política de la educación de las áreas referidas (Escobar Marulanda, 2006), que invitaría a indagar sobre las escuelas públicas y privadas que imparten criminología (Zaffaroni, 1990). 
una propuesta de renovación

Education theory and education sciences applied to the criminology:

a renewal propose

A este respecto, apunta Zaffaroni: "Es obvio que la investigación criminológica en América Latina no alcanza los niveles cualitativos ni cuantitativos de los países centrales, debido a los escasos recursos que se destinan a la misma y al limitado impulso oficial” (1990, pág. 69).

Por otro lado, desde la dimensión filosófica, cabe plantearse cuál es la misión, justificación, perspectiva, intención, fundamentación. Y de la dimensión proyectiva (Colom Cañellas y Rodríguez Cruz, 1996), la visión, nuevamente misión, qué alcances tiene, qué se busca con su enseñanza e implementación, cuál es la perspectiva de los egresados en su función social (Cantú Medonza, 2015).

Por parte de la dimensión teórico-práctica, como se mencionó anteriormente, la aplicación de modelos didácticos, organización escolar, orientación, y considerando la Perspectiva dinámica o diacrónica de la endoestructura de las Ciencias de la Educación de los mismos autores (Colom Cañellas y Rodríguez Cruz, 1996, pág. 50), esquemas educativos, proyectos de investigación, planificación, metodología, y aplicación, de las cuales, están muy laxas (Escobar Marulanda, 2006; Zaffaroni, 1990).

De ello, como afirman Colom Cañellas y Rodríguez Cruz (1996), “en la medida que la actividad educativa intencional crea nuevas opciones, en la medida en que el dinamismo inherente a esa actividad educativa pueda romper caducos esquemas y crear nuevos planteamientos y paradigmas (...)” (pág. 53), habrá espacio para que la criminología aplique todo lo que comprende la teoría de la educación y mejoren conforme la realidad social.

\section{LA ENSEÑANZA UNIVERSITARIA DE LA CRIMINOLOGÍA Y SU PERTINENCIA SOCIAL}

Los estudios universitarios de la criminología, obedecen a una necesidad de atender un fenómeno de la sociedad que implica focalizar la atención por parte de las instituciones educativas, en este caso, la violencia y criminalidad (Abbot Matus, 2007; Zaffaroni, 1990). Las escuelas públicas y privadas tienen primordialmente el compromiso social de formar a los educandos, darles las herramientas para su autocivilización y ser transmisores de buenas costumbres (Escobar Marulanda, 2006).
La enseñanza de la criminología debe generar profesionales comprometidos con las acciones más lastimosas para la sociedad, entender el fenómeno criminal, desmenuzarlo y encontrar los elementos que lo ocasionan, para con esto, proponer las estrategias que protejan a las sociedades de la autolesión (Abbot Matus, 2007). El docente debe fomentar la empatía, influir positivamente (Salgado, 2013).

Estas funciones de la criminología las clarifica Ríos Patio (2017) al apuntar la esencial e importante labor que esta persigue como fin último: "La búsqueda de las causas de la criminalidad, que constituye la finalidad de la criminología, es un verdadero problema nacional" (pág. 72). El mismo autor reflexiona sobre la incertidumbre que está latente en los sistemas de gobierno al no prestar atención a la implementación de los conocimientos transformadores de la criminología, basándose el régimen político en mera represión.

En diversas partes de América Latina, se han introducido los conocimientos de Europa (Zaffaroni, 1990) sobre las ciencias criminales, principalmente de la antropología criminal, psicología criminal, sociología criminal, biología criminal y la recién nacida criminología, además de la criminalística (Molina Arrubla, 1988), esto, para atender una realidad social que se vivía en aquel momento y que en la actualidad no ha cesado, me refiero a la violencia y criminalidad. Apunta Abbot Matus: "La creación de carreras y áreas de conocimiento habrá entonces de estar determinada por las condiciones de tal demanda" (2007, pág. 19).

Puntualiza Zaffaroni: "Entiendo que corresponde a la criminología una importantísima función en el futuro inmediato de América Latina, porque reúne el conocimiento $-\mathrm{o}$ debe reunirlo o procurarloque es indispensable para hacer descender los niveles de violencia del control social en la región” (1990, pág. 70).

Crear profesionales con visión de prisma que permita visualizar la desorganización social, los problemas que ocurren en esta, la dinámica e interacción de todos los actores sociales, conocer sus componentes. Los profesionales de la criminología deben ser conscientes de la gravedad de problemas con los que tratarán, por lo que les requiere una alta capacitación en 
valores, ética, respeto, empatía, compromiso (Escobar Marulanda, 2006). Los conocimientos básicos pueden fundamentarse en tres formas de docencia: Docencia de conocimientos, docencia de capacidades intelectuales y docencia de valores y actitudes (Abbot Matus, 2007, pág. 37).

El criminólogo debe ser capaz de realizar investigaciones científicas, extraer información de fuentes estadísticas o del campo, para encaminar sus acciones en base justificada sobre el objeto de estudio (Escobar Marulanda, 2006). "No se trata ya de indicar qué temas y cuántas horas se han pasado los alumnos y profesores en clase, sino de ver qué saben y qué saben hacer los alumnos" (Escobar Marulanda, 2006, pág. 3).

También es importante aclarar y trabajar sobre la identidad profesional de un criminólogo, pues este es visto indistintamente como policía, detective, médico forense, perito, etcétera (Escobar Marulanda, 2006). Finalmente: “Ante un escenario de tamaños cambios, negarse al cambio sería morir" (Abbot Matus, 2007, pág. 17). Atinadamente, Ríos Patio (2017) define el actuar de la criminología a través de una composición teórica-poética: "La criminología tiene un carácter holístico, no reduccionista, dinámico, empírico, científico social y político, que le permite buscar en el ámbito natural del hombre, que es el social y político, las causas de su comportamiento criminal en una multiplicidad de fuentes (...)” (pág. 76).

\section{CONCLUSIONES}

De algunas reflexiones sobre la teoría de la educación, se tomaron de referencia para aplicarlas a la enseñanza universitaria de la criminología, también se notó la especialización de esta en las ciencias de la educación, al generar procesos particulares para su enseñanza en las aulas $\mathrm{y}$ otras esquemas educativos y de proyectos, así como investigaciones. Se destacaron las áreas de oportunidad y el replanteamiento que tendrían la criminología educativa y criminología pedagógica, para que en base a la enseñanza, reforzar el compromiso social de formar profesionales generadores de conocimiento sobre la criminalidad y que estos con alto valor ético, colabore con las agencias públicas, privadas y sociedad, para atender el problema criminal.

\section{FUENTES DE INFORMACIÓN}

\section{Fuentes bibliográficas}

Calixto Contreras, Y. (2017). Criminología Educativa. Murcia: Diego Marín.

Cantú Mendoza, R. (2015). Nuevos retos a la gestión de la educación superior en México. En Cantú Mendoza, R. (coord). La Responsabilidad Social de las Universidades Contemporáneas (pp. 13-38). San Nicolás de los Garza: Universidad Autónoma de Nuevo León y Editorial Itaca.

\section{Fuentes electrónicas}

Abbot Matus, F. (2007). En torno a la enseñanza de la criminología y las ciencias jurídicas en España: Una coyuntura y un desafío en el fondo y en la forma. 9(5). Academia. Revista Sobre Enseñanza del Derecho. 13-54. Recuperado de http://www.derecho.uba.ar/publicaciones/ rev_academia/revistas/09/en-torno-a-laensenanza-de-la-criminologia-y-las-cienciasjuridicas-en-espana.pdf

Colom Cañellas, A.J. y Rodríguez Cruz, M.P. (1996). Teoría de la educación y ciencias de la educación: Carácter y ubicación. 8. Teoría de la Educación. Revista Interuniversitaria. 43-54. Recuperado de http://revistas.usal.es/ index.php/1130-3743/article/view/3087/3117

Escobar Marulanda, G. (2006). La enseñanza en criminología. Algunas consideraciones. 8. Revista Electrónica de Ciencia Penal y Criminología. 1-8. Recuperado de http:// criminet.ugr.es/recpc/08/recpc08-r2.pdf

Molina Arrubla, C.M. (1988). Evolución histórica de la criminología: Ensayo de criminología académica. Primera Parte. Revista Facultad de Derecho y Ciencias Políticas. 80. 123-165. Recuperado de https://dialnet. unirioja.es/servlet/articulo? codigo $=5509509$

Ríos Patio, G. (2017). La herencia de la criminología clínica. Horizonte Médico, 17(2), 71-76. Recuperado de https://www.redalyc. org/pdf/3716/371651249011.pdf 
Education theory and education sciences applied to the criminology:

a renewal propose

Salgado, A. (2013). Construyendo el concepto de pedagogía criminológica. Criminología y Justicia. Recuperado de https://cj-worldnews. com/spain/index.php/es/criminologia-30/ menores-y-violencia/item/2518-construyendoel-concepto-de-pedag og \% C 3\% ADacriminol $\% \mathrm{C} 3 \% \mathrm{~B} 3$ gica
Zaffaroni, E.R. (1990). La enseñanza universitaria de la criminología en América Latina. 3. Eguzkilore. Cuaderno del Instituto Vasco de Criminología. 5971. Recuperado de https://www.ehu.eus/ documents/1736829/2164896/08+-+La+ensen anza + universitaria + de + la + criminologia.pdf 